Arab World English Journal (AWEJ) Volume 12. Number2 June 2021

DOI: https://dx.doi.org/10.24093/awej/vol12no2.5

Pp. $72-82$

\title{
Development of Speaking Skills Assessment Criteria for Engineering Students
}

\section{Zoia Kornieva}

Department of the English Language Theory, Practice and Translation,

National Technical University of Ukraine "Igor Sikorsky Kyiv Polytechnic Institute”, Kyiv,

Ukraine

\section{Olha Vashchylo}

Department of the English Language Theory, Practice and Translation, National Technical University of Ukraine "Igor Sikorsky Kyiv Polytechnic Institute", Kyiv, Ukraine

Received: $2 / 18 / 2021$

Accepted: 5/12/2021

Published:6/24/2021

\section{Abstract}

The purpose of the article is to put forward English monologue production assessment criteria to verify the efficiency of the devised methodology of teaching English for future mechanical engineers. In the course of the research, theoretical, empirical, and statistical methods have been used. Various approaches to identifying the assessment criteria have been thoroughly analyzed. Seven criteria to assess the monologue production skills, five primary and two secondary ones, have been suggested. The allocation of the points by every criterion according to the devised scales have been elucidated. The proposed assessment criteria were used in the methodological experiment that was held at Igor Sikorsky Kyiv National Technical University. The experiment in question aimed to verify the efficiency of the devised methodology of teaching English monologue production to students majoring in mechanical engineering. Three experimental groups, 34 students in total, studying in their final year of Bachelor studies within the Subject Areas of Applied Mechanics and Industrial Engineering, participated in the methodological experiment. The conducted experiment confirmed the efficiency of the methodology proposed. Keywords: assessment criteria, engineering students, methodological experiment, National Technical University of Ukraine, speaking skills

Cite as: Kornieva, Z., \& Vashchylo, O. (2021). Development of Speaking Skills Assessment Criteria for Engineering Students. Arab World English Journal, 12 (2) 72 -82.

DOI: https://dx.doi.org/10.24093/awej/vol12no2.5 


\section{Introduction}

Mastering a foreign language has become an intrinsic part of a modern engineer's training. First and foremost, it is connected with Ukraine participating in the Common European Zone to ensure the highest possible quality of the tertiary education, facilitate the collaboration between European Universities, increase the competitiveness on the labor market.

Furthermore, the importance of mastering a foreign language is facilitated by the international collaboration between higher educational institutions. This envisages participation in various student exchange programs, on-the-job training programs, collaborative publishing activities; conducting joint scientific research; organizing international conferences, conventions, workshops; launching diverse collaborative educational and scientific programs with foreign educational institutions (Verkhovna Rada of Ukraine, 2014).

It is essential to note that Ukraine aims to improve the global relationships by broadening the international connections in the spheres of economy, science, and technology; ensuring industrial and commercial collaboration with foreign partners; participation in scientific and technical exhibitions, conferences, economic summits. The above stated demonstrates an increasing demand for technical specialists that can speak a foreign language fluently, thus, realizing the communicative intentions effectively in the professional sphere.

However, the foreign language constituent in the curriculum of the overwhelming majority of technical universities in Ukraine amounts to two academic hours per week, which is insufficient to attain the required level of language competence. Hence, the development of new methodologies of teaching a foreign language, namely English, to future engineers that can facilitate the teaching process through the information and communication technology, i.e., podcasting, implementation is of the utmost importance.

Verifying the efficiency of new methodologies of teaching, it is crucial to highlight the criteria of assessing the students' competence formation. The above stated determines the topicality of the study. The purpose of the given article is to put forward English monologue production assessment criteria for engineering students and focus on the specificity of the points allocation by every criterion to verify the efficiency of the methodology devised.

\section{Literature Review}

The issue of the methodologies development that envisages the use of podcasting has been considered by such authors as Gura (2006), Stanley (2006), Dudeney and Hockly (2007), Edirsingha, Salmon and Nie (2008), Kavaliauskienè and Anusienė (2009), Travis and Joseph (2009), Waragai, Ohta and Raindl (2010), Protazanova (2013), Sysoiev (2014), Qaddour (2017) and others. A podcast, i.e., audio or a video file created and uploaded to the World Wide Web by any Internet user, was chosen as a tool to facilitate the speaking skills development. Despite the existing number of scientific works, the methodology of teaching English monologue production to future mechanical engineers that envisages the use of podcasting has not been devised yet. Having developed the methodology, it is essential to verify its efficiency by conducting a methodological experiment based on the established criteria for the monologue speech assessment. 
The analysis of the methodological literature reveals that the speaking skills assessment is a subjective phenomenon: Cohen (1994), Fedorova (2006), Fucher and Davidson (2007), Bachman and Palmer (2010), Carr (2011), Konotop (2011).

Therefore, to ensure greater objectivity, there appears a necessity to establish a set of criteria to assess monologue speech produced by students. There is no standard classification of the criteria to assess the monologue production skills available at present. Every scientist suggests their assessment scale, dependent upon the specificity of the methodology devised. According to Halskova and Hez (2006):

While assessing the monologue production skills, it is vital to take into account the following: the diversity of the vocabulary range and the grammatical structures used, the accuracy of their usage; extension, and consistency; relevance of the language means to the communicative situation; speech duration; the realization of the speech intention; the number of sentences expressing personal attitude to the problem in question. (p.223)

Borisko (1987) distinguishes between the qualitative criteria (logical and structural systematization and coherence, situational relevance, modality, intentionality, topic correspondence, and informativity, language accuracy) and the quantitative criteria (speech duration, its rate, and fluency). Ustymenko (2013, p. 12) considers it appropriate "...to evaluate the monologue speech according to the following criteria: relevance to the topic (situation), type of monologue, the communicative intention realization, speech duration and tempo, variety of speech patterns, degree of coherence, consistency, and argumentation, structural and compositional integrity, creative aspects, phonetic, lexical, grammatical and stylistic speech accuracy."

It is stated in the National ESP Curriculum for Universities (Bakaieva, 2005, p. 24) that "students' speech behavior is assessed according to the following criteria: arrangement of what and how is said in terms of quantity, quality, relevance, and clarity of the information; accuracy and appropriateness of the language means used; lexical and grammatical range; logical sequence; speech duration; ability to articulate, demonstrate the required emphasis, rhythm, intonation." To assess oral speech production, the Common European Framework of Reference for Languages Learning, Teaching and Assessment (Nikolaeva, 2003) recommends applying the following parameters: "speech tempo, coherence, communicative intention realization, accuracy, lexical range, grammatical accuracy" (p. 193). It is also indicated that "any practical control system, regardless of the approach used, requires limiting the number of possible categories to an acceptable level; the highest psychologically accepted level is restricted to seven categories, as an increase in their number inevitably leads to mental overstrain." All in all, the question of assessing monologue production has been put forward.

\section{Method}

During the research, theoretical, empirical, and statistical methods were used. The theoretical methods included analysis, synthesis, and systematization of the psychological, linguistic, and methodological works. The empirical methods encompassed pedagogical observation, experimental teaching, pre-experimental and post-experimental assessments, processing the data received. The statistical methods implied the acquired data processing by methods of 
mathematical statistics with its further qualitative and quantitative analysis to prove the efficiency of the methodology devised.

\section{Participants}

The experiment was held at Igor Sikorsky Kyiv National Technical University. Three experimental groups (EG), that is 34 students in total, studying in their final year of Bachelor studies within the Subject Areas Applied Mechanics and Industrial Engineering at the Institute of Mechanical Engineering, participated in the methodological experiment.

\section{Instruments}

To ensure that the level of competence formation is approximately the same in all the experimental groups before the experiment, the Student's t-test (to compare the average results of the two unpaired samples) and the F-test (to verify the similarity of the variance) were used. To verify the efficiency of the devised methodology of teaching in general, the statistical criterion $\varphi^{*}$ - Fisher z-transformation was used, whereas to verify the efficiency of the methodology in every experimental group, the Student's t-test for the paired samples was used. As different methodology variants were proposed in every experimental group during the methodological experiment Fisher z-transformation was used to identify the most efficient one.

\section{Procedures}

The conducted methodological experiment is seen as vertical and horizontal. The vertical character of the experiment implies that the level of the students' communicative competence formation in monologue production is assessed before and after the experimental teaching. The horizontal character of the experiment entails the most effective methodology variant elicitation. To realize the purpose of the methodological experiment the following steps are to be taken: to devise the monologue production assessment criteria; to conduct the pre-experimental and postexperimental assessments after the experiment; to process the data received in the course of the experiment, to analyze the results, to draw conclusions.

\section{Results}

Regarding the existing experience and current regulations and standards, considering the recommendations on limiting the number of the assessment criteria, seven criteria (five primary criteria and two secondary ones) for assessing the monologue production skills of future engineers have been put forward. The criteria, as well as the points allocation by every criterion, are stated in table one.

Table 1. Points allocation by the speaking skills assessment criteria

\begin{tabular}{|c|l|c|}
\hline № & \multicolumn{1}{|c|}{ Speaking skills assessment criteria } & $\begin{array}{c}\text { Maximum } \\
\text { points }\end{array}$ \\
\hline 1. & Communicative intention relevance & 20 \\
\hline 2. & Structural completeness of the speech & 15 \\
\hline 3. & Adequacy of the professional terminology used & 15 \\
\hline 4. & Accuracy of the language means & 15 \\
\hline 5. & Coherence and cohesion & 15 \\
\hline 6. & Speech rate & 10 \\
\hline 7. & Speech duration & 10 \\
\hline Total & & 100 \\
\hline
\end{tabular}


The criteria specified in the table and the procedure of the points allocation by every criterion while assessing the monologue speech produced by students are to be examined thoroughly.

\section{Communicative intention relevance}

The speech has to correlate with the topic; the key issues are to be covered extensively; the elements of analysis, reflection, justification have to be included to realize the communicative intention in one of the professional situations. According to Sklyarenko (1995), the criterion of communicative intention relevance should have the highest value in oral speech production assessment. Due to this, 20 points are allocated by this criterion.

To calculate the points by the criterion the coefficient of the communicative intention relevance $\left(\mathrm{C}_{\mathrm{CIR}}\right)$ is applied. The following coefficient is calculated by the formula $\mathrm{C}_{\mathrm{CIR}}=\mathrm{A}_{1} / \mathrm{A}_{2}$, where $A_{1}$ is the number of sentences aimed at expressing the communicative intention, $A_{2}$ is the total number of sentences in the speech (Kirzhner, 2009). The points by the criterion are calculated using the formula: $\mathrm{P}_{\mathrm{CIR}}=\mathrm{C}_{\mathrm{CIR}} \times \mathrm{P}_{\mathrm{MCIR}}$, where $\mathrm{P}_{\mathrm{CIR}}-$ the number of points received by a student, $\mathrm{P}_{\mathrm{MCIR}}=20$ - the maximum number of points by the specified criterion. An example of the point allocation procedure is given in table two.

Table 2. Points allocation by the communicative intention relevance criterion

\begin{tabular}{|c|c|c|c|c|c|c|c|c|c|c|}
\hline $\mathrm{C}_{\mathrm{CIR}}$ & 1 & 0,9 & 0,8 & 0,7 & 0,6 & 0,5 & 0,4 & 0,3 & 0,2 & 0,1 \\
\hline Points & 20 & 18 & 16 & 14 & 12 & 10 & 8 & 6 & 4 & 2 \\
\hline
\end{tabular}

\section{Structural completeness of the speech}

The compulsory structural elements of the monologue (introduction, main part, and conclusion) are to be presented consistently. They are to contain the problem statement, the topicality of the research, the introduction of key concepts and facts statement, the suggestions on how to solve the problem in question. It is essential to divide the text of the speech into micro texts regarding the issues highlighted. The assessment procedure by the criterion of Structural completeness of the speech is carried out by the scale presented in table three.

Table 3. The assessment scale by the criterion of structural completeness of the speech

\begin{tabular}{|l|l|}
\hline Points & Descriptor \\
\hline $15-12$ & Requirements to the speech structure are met to the full extent. \\
\hline $11-8$ & Requirements to the speech structure are met to a sufficient degree. \\
\hline $7-4$ & Requirements to the speech structure are met partially. \\
\hline $3-0$ & Requirements to the speech structure are not met. \\
\hline
\end{tabular}

\section{Adequacy of the professional terminology used}

This criterion aims to evaluate the students' ability to accurately use scientific and professional terms to realize the communicative intention.

To calculate the points by the criterion it is necessary to introduce the coefficient of the professional terminology used $\left(\mathrm{C}_{\mathrm{PT}}\right)$, which is calculated by the formula $\mathrm{C}_{\mathrm{PT}}=\mathrm{B}_{1} / \mathrm{B}_{2}$, where $\mathrm{B}_{1}$ is the number of sentences with the aptly used professional terms, $B_{2}$ is the total number of sentences in the speech (Kirzhner, 2009). The points by the criterion are calculated using the formula: $\mathrm{P}_{\mathrm{PT}}=\mathrm{C}_{\mathrm{PT}} \mathrm{x} \mathrm{P}_{\mathrm{MPT}}$, where $\mathrm{P}_{\mathrm{PT}}$ is the number of points received by a student, $\mathrm{P}_{\mathrm{MPT}}=15-$ 
the maximum number of points by the criterion. An example of the point allocation is given in table four.

Table 4. Points allocation by the adequacy of the professional terminology used criterion

\begin{tabular}{|c|c|c|c|c|c|c|c|c|c|c|}
\hline $\mathrm{C}_{\mathrm{PT}}$ & 1 & 0,9 & 0,8 & 0,7 & 0,6 & 0,5 & 0,4 & 0,3 & 0,2 & 0,1 \\
\hline Points & 15 & 13,5 & 12 & 10,5 & 9 & 7,5 & 6 & 4,5 & 3 & 1,5 \\
\hline
\end{tabular}

\section{Accuracy of the language means}

It means the formation of the foreign language phonetic, lexical, and grammatical competencies at an advanced level that. It encompasses, in particular, the ability to operate complex syntactic constructions efficiently, adherence to the phonetic, intonation norms of the modern English language (Protazanova, 2013).

To calculate the points by the criterion the coefficient of the accuracy of the language means $\left(\mathrm{C}_{\mathrm{ALM}}\right)$ is to be used. The coefficient is calculated by the formula $\mathrm{C}_{\mathrm{ALM}}=\mathrm{C}_{1} / \mathrm{C}_{2}$, where $\mathrm{C}_{1}$ is the number of phrases containing mistakes, $\mathrm{C}_{2}$ - total number of sentences in the monologue. The points by the criterion are calculated using the formula: $\mathrm{P}_{\mathrm{ALM}}=\mathrm{C}_{\mathrm{ALM}} \times \mathrm{P}_{\mathrm{MALM}}$, where $\mathrm{P}_{\mathrm{ALM}}$ is the number of points received by a student, $\mathrm{P}_{\mathrm{MALM}}=15-$ the maximum number of points by the specified criterion. An example of the point allocation is given in table five.

Table 5. Points allocation by the accuracy of the language means criterion

\begin{tabular}{|c|c|c|c|c|c|c|c|c|c|c|}
\hline $\mathrm{C}_{\mathrm{ALM}}$ & 1 & 0,9 & 0,8 & 0,7 & 0,6 & 0,5 & 0,4 & 0,3 & 0,2 & 0,1 \\
\hline Points & 15 & 13,5 & 12 & 10,5 & 9 & 7,5 & 6 & 4,5 & 3 & 1,5 \\
\hline
\end{tabular}

\section{Coherence and cohesion}

Assessing the monologues produced by the students in terms of coherence, it is necessary to account for the efficiency of arranging logical and structural elements in the speech, the causeand-effect relations, absence of abrupt switches from one topic to another.

Based on the approach suggested by Borysko (1987), the students' skills to actively and aptly use appropriate means of cohesion to sustain the logical and structural integrity of the speech are accounted for while assessing the degree of coherence. Halperin (2007) defines cohesion as a unique linking means that ensure continuity: logical sequence (temporal or spatial), interdependence of certain statements, facts, actions, and events. The cohesion of such elements in the text as sentences, supra-phrasal units, and paragraphs is measurable first and foremost (Lytneva, 1992).

It is necessary to scrutinize the specifics of the points allocation by the criterion coherence and cohesion of the speech according to the scale presented in table six.

Table 6. Points allocation by the coherence and cohesion criterion

\begin{tabular}{|c|c|c|}
\hline Coherence and cohesion & Coherence & Linking words and phrases \\
\hline Points & 10 & 5 \\
\hline Total number of points & \multicolumn{2}{|c|}{15} \\
\hline
\end{tabular}

The total number of points by the criterion is calculated by summing the points for the degree of coherence and the linking words and phrases used in the speech. 
The points by the degree of coherence are calculated as follows:

10 - 9 Requirements to the degree of coherence are met to the full extent;

8 - 6 Requirements to the degree of coherence are met to a sufficient degree;

5 - 3 Requirements to the degree of coherence are met partially;

2 - 0 Requirements to the degree of coherence are not met.

To assess the speech by the availability of the linking words and phrases, the coefficient of cohesion $C_{L}$ is used. The coefficient is calculated by the formula: $C_{L}=N_{1} / N$, where $N_{1}$ is the number of the linkers used in the speech, $\mathrm{N}$ is the total number of sentences. The coefficient of cohesion $\mathrm{C}_{\mathrm{L}}$ is expressed as points by the scale presented in table seven.

Table 7. Points allocation by the linking words and phrases availability

\begin{tabular}{|c|c|c|c|c|c|c|}
\hline $\mathrm{C}_{\mathrm{L}}$ & 1 & $0,9-0,8$ & $0,7-0,6$ & $0,5-0,4$ & $0,3-0,2$ & $0,1-0$ \\
\hline Points & 5 & 4 & 3 & 2 & 1 & 0 \\
\hline
\end{tabular}

\section{Speech rate}

The rate of speech helps to determine the speed of reaction, which specifies, in its turn, the degree of the speech operations automation. The speech rate is individual and is referred to by some scientists as a secondary criterion, while it does not remarkably affect the success of the communicative intention realization (Lytneva, 1992).

According to the scientific data, the speech rate of a British native speaker amounts to 3.165.33 syllables per second (Stepanova, 2011), the speech rate of an American native speaker, according to Laver (1994), ranges from 3.1 to 5.4 syllables per second, which is 230 syllables per minute on average. However, we believe that a student who is studying English as a foreign language in the fourth year at a technical educational institution cannot be compared to a native speaker. Therefore, assessing the speech of the students by the specified criterion, based on the approach suggested by Pashchuk (2002), the speech rate of 125-130 syllables per minute will be accepted as a norm. The points calculation by the criterion of the speech rate is carried out according to the scale presented in table eight.

Table 8. Points allocation by the speech tempo criterion

\begin{tabular}{|c|c|c|c|c|c|c|c|c|}
\hline $\begin{array}{c}\text { Syllables } \\
\text { per minute }\end{array}$ & $130-125$ & $124-120$ & $119-115$ & $114-110$ & $109-105$ & $104-100$ & $99-95$ & $94-90$ \\
\hline Points & 10 & 9 & 8 & 7 & 6 & 5 & 4 & 3 \\
\hline
\end{tabular}

\section{Speech duration}

Assessing monologues by the criterion in question, we rely upon the approach suggested by Skalkin (1983) and consider 4-6 complete sentences to be inherent to a fragmentary speech, 7-12 sentences - to a monologue speech unit, 13-20 sentences - to an extended monologue. The points allocation by the criterion is carried out according to the scale presented in table nine.

Table 9. Points allocation by the speech duration criterion

\begin{tabular}{|c|c|c|c|c|c|}
\hline Number of sentences & 13 and more & $12-10$ & $9-8$ & $7-6$ & $5-4$ \\
\hline Points & 10 & 8 & 6 & 4 & 2 \\
\hline
\end{tabular}




\section{Discussion}

The assessment of the monologues produced by students was carried out by the assessment criteria highlighted above while conducting the methodological experiment. The experiment aimed to verify the efficiency of the devised methodology of teaching English monologue production to students majoring in mechanical engineering. The experiment was held at Igor Sikorsky Kyiv National Technical University; three experimental groups (EG), 34 students in total, studying in their final year of Bachelor studies within the Subject Areas Applied Mechanics and Industrial Engineering, participated in the methodological experiment.

The conducted methodological experiment is vertical and horizontal (the classification by Gurvych, 1980). The vertical character of the experiment implies that the level of the communicative competence formation in monologue production is assessed before and after the experimental teaching. The horizontal character of the experiment entails the most effective methodology variant elicitation.

The invariable conditions of the experimental teaching incorporate the aim and the content of the monologue production teaching, the content of the pre-and post-experimental assessment, the speech assessment criteria, the duration of the experimental teaching, the list of participants, the experimenter.

The variable conditions of the experiment encompassed different percentages of tasks on partial and detailed rendering of the information from the comprehended podcast. As the tasks on the semantic analysis serve as a basis for students' monologue production, their allocation was equal in all three groups. Thus, in EG 1 - the percentage of tasks on partial rendering of the information from the podcast is twice as big as the percentage of tasks on the detailed rendering of the content (the correlation is 2:1). In EG 2 - the percentage of tasks on partial rendering of the information equals the percentage of tasks on the detailed rendering of the content (the correlation is 1:1). In EG 3 - the percentage of tasks on the detailed rendering of the content is twice as big as the percentage of tasks on partial rendering of the information (the correlation is $1: 2)$.

The pre-experimental assessment results indicate an insufficient degree of the communicative competence formation in monologue production. Stusents' speech did not always correlate with the topic; the problem elucidation was not extensive; the problem-statement was frequently inadequate etc. The experimental teaching, which lasted 28 hours in total (with 14 hours dedicated to extracurricular studies), was conducted through the methodology devised within the module Machine Building Technological Process Planning and its units. Students spent 45-50 minutes of every class performing the tasks by the methodology. The rest of the time they worked according to the curriculum. The aim of the post-experimental assessment was to establish the degree of future mechanical engineers' communicative competence formation in monologue production after the experimental teaching. The average results of the pre-and postexperimental assessments are shown in table ten. 
Table 10. Average results of the pre-experimental and post-experimental assessments in the experimental groups EG-1, EG-2, EG-3

\begin{tabular}{|c|c|c|c|c|c|c|c|c|c|}
\hline \multirow[b]{2}{*}{$\begin{array}{l}\text { Experimental } \\
\text { group }\end{array}$} & \multicolumn{9}{|c|}{ Results by the monologue production assessment criteria, in points } \\
\hline & 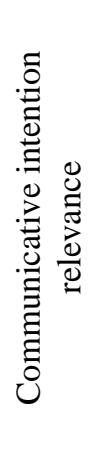 & 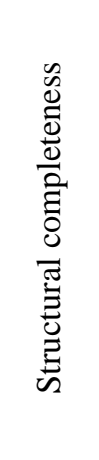 & 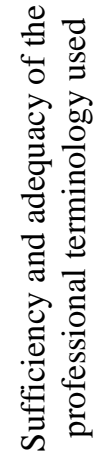 & 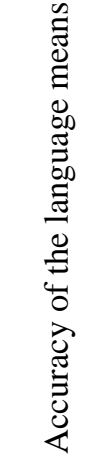 & 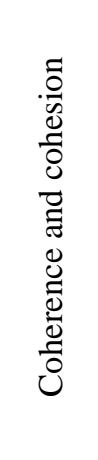 & 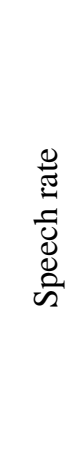 & 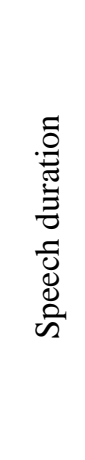 & $\begin{array}{l}\mathscr{0} \\
0 \\
0\end{array}$ & 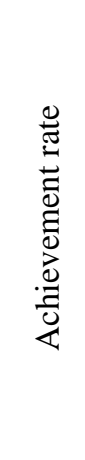 \\
\hline EG-1 Post-EA & 15,64 & 11,36 & 11,00 & 10,18 & 11,45 & 8,73 & 8,36 & 76,73 & 0,77 \\
\hline EG-1 Pre-EA & 11,36 & 8,45 & 8,64 & 7,18 & 7,00 & 7,55 & 7,64 & 57,82 & 0,58 \\
\hline Increase & 4,28 & 2,91 & 2,36 & 3 & 4,45 & 1,18 & 0,72 & 18,91 & 0,19 \\
\hline EG-2 Post-EA & 16,3 & 12,2 & 11,8 & 11,9 & 12,2 & 8,5 & 8,9 & 81,8 & 0,82 \\
\hline EG-2 Pre-EA & 12,8 & 8,5 & 8,2 & 7,5 & 8,2 & 7,5 & 7,3 & 60 & 0,6 \\
\hline Increase & 3,5 & 3,7 & 3,6 & 4,4 & 4 & 1 & 1,6 & 21,8 & 0,22 \\
\hline EG-3 Post-EA & 16,92 & 13,38 & 12,54 & 12,15 & 12,08 & 8,85 & 8,85 & 84,77 & 0,85 \\
\hline EG-3 Pre-EA & 14,08 & 8,23 & 8,54 & 7,77 & 8,38 & 7,15 & 6,92 & 61,08 & 0,61 \\
\hline Increase & 2,84 & 5,15 & 4 & 4,38 & 3,7 & 1,7 & 1,93 & 23,69 & 0,24 \\
\hline Maximum points & 20 & 15 & 15 & 15 & 15 & 10 & 10 & 100 & 1 \\
\hline
\end{tabular}

In the table, the abbreviation is used: EA -experimental assessment.

The received data has been processed by mathematical statistics methods, quantitative and qualitative analysis. The quantitative analysis made it possible to state that all the experimental groups reached the achievement coefficient of 0.7 and more. This is considered sufficient by Bespalko (1968). The comparison of the achievement coefficient values (pre-experimental and post-experimental assessments) showed the significant increase in all the experimental groups: an increase by 0.19 in EG-1, by 0.22 in EG-2, by 0.24 in EG-3. The maximum increase of the achievement coefficient value was stated in EG-3, which confirmed higher efficiency of the third variant of the methodology proposed. The qualitative analysis showed that an increase of the achievement coefficient value (post-experimental teaching was induced by the speech quality improvement (criteria of coherence and cohesion, structural completeness, accuracy of the language means).

\section{Conclusion}

The article is devoted to the question of putting forward the speaking skills assessment criteria to verify the efficiency of the devised methodology. A thorough analysis of the theoretical and practical studies on the speaking skills assessment has been conducted in the article; five primary criteria (communicative intention relevance, structural completeness of the speech, adequacy of the professional terminology used, accuracy of the language means, coherence and cohesion) and two secondary criteria (speech rate and its duration) to assess the speaking skills have been proposed, the peculiarities of the points allocation by these criteria have been specified. The specificity of using the highlighted assessment criteria in the methodological experiment held at 
Igor Sikorsky Kyiv National Technical University has been regarded in the article. The prospects for further research encompass highlighting and justifying the criteria for assessing the students' competence formation in the other skills (dialogue production, listening, reading, writing) with the corresponding points allocation scale development.

\section{About the authors}

Zoia Kornieva is a Doctor of Pedagogy, Full Professor at Department of the English Language Theory, Practice and Translation, Faculty of Linguistics at National Technical University of Ukraine "Igor Sikorsky Kyiv Polytechnic Institute" in Kyiv, Ukraine. Her professional and research interests lie in the area of immersion, BE and EFL teaching as well as modern English lexicology and lexicography. https://orcid.org/0000-0002-8848-4323

Olha Vashchylo is a Candidate of Pedagogical Sciences, Senior Lecturer at Department of the English Language Theory, Practice and Translation, Faculty of Linguistics at National Technical University of Ukraine "Igor Sikorsky Kyiv Polytechnic Institute" in Kyiv, Ukraine. Her research and teaching interests include Language Learning and Acquisition, Second Language Acquisition, Information and Communication Technology Implementation into the Educational Process. https://orcid.org/0000-0001-7484-9435

\section{References}

Bakaieva, H., et al. (2005). ESP Study Program. Kyiv, Ukraine: Lenvit.

Bachman, L., \& Palmer, A. (2010). Language Assessment in Practice. Oxford: Oxford University Press.

Bespalko, V. (1968). Practice of the Knowledge Assessment Criteria Development and Application. Soviet Pedagogy, 4, 52-69.

Borysko, N. (1987). Teaching German Monologue Production Using Video within an Intensive Course, (Unpublished Doctoral Dissertation). Kyiv State Pedagogical Institute of Foreign Languages, Kyiv, Ukraine.

Carr, N. (2011). Designing and Analyzing Language Tests. Oxford: Oxford University Press.

Cohen, A. (1994). Assessing Language Ability in the Classroom. Boston, MA: Heinle \& Heinle Publishers.

Dudeney, G., \& Hockly, N. (2007). How to Teach English with Technology. London: Pearson Longman.

Edirisingha, P., Salmon, G., \& Nie, M. (2008). Developing pedagogical podcasts. In G. Salmon \& P. Edirisingha (Eds.), Podcasting for learning in universities (pp. 153-168). Berkshire, England: Open University Press.

Fedorova, I. (2006). Teaching English Narrative Speaking Skills to Future International Economists, (Unpublished Doctoral Dissertation). Kyiv National Linguistic University, Kyiv, Ukraine.

Fucher, G., \& Davidson, F. (2007). Language testing and assessment: an advanced resource book. London, UK \& New York, NY: Routledge.

Gura, M. (2006). Moving Instructional Podcasting beyond Coursecasting. Perspectives: New York Journal of Adult Learning, 4(2), 31-33.

Gurvich, P. (1980). Theory and practice of the experiment in language teaching. Vladimir, Russian Federation: VGPU.

Halperin, I. (2007). Text as an Object of a Linguistic Research. Moscow: KomKniga. 
Halskova, N., \& Hez, N. (2006). Theory of the Foreign Languages Teaching: Linguodidactics and Methodology. Moscow: Academia.

Kavaliauskienè, G., \& Anusienè, L. (2009). English for Specific Purposes: Podcasts for Listening Skills. Santalka: Filologija. Edukologija, 17(2), 28-37. DOI: 10.3846/1822430X.2009.17.2.28-37

Kirzhner, S. (2009). Teaching Future Lawyers English Monologue Production Using Authentic Video, (Unpublished Doctoral Dissertation). Kyiv National Linguistic University, Kyiv, Ukraine.

Konotop, O. (2011). Dialogue Production Assessment Criteria for Future Philologists. Theoretical Issues of Culture and Education, 44, 69-71.

Laver, J. (1994). Principles of Phonetics. Cambridge: Cambridge University Press.

Lytneva, A. (1992). Teaching Monologue Production upon the Mass Media Materials in a Higher Technical Educational Establishment, (Unpublished Doctoral Dissertation). Kyiv State Pedagogical Institute of Foreign Languages, Kyiv, Ukraine.

Nikolaeva, S. (Ed.) (2003). Common European Framework of Reference for Languages: Learning, Teaching, Assessment. Kyiv, Ukraine: Lenvit.

Pashchuk, V. (2002). Teaching English Monologue Production to Future Philologists Using Authentic Feature Films, (Unpublished Doctoral Dissertation). Kyiv National Linguistic University, Kyiv, Ukraine.

Protazanova, N. (2013). Criteria to Assess Educational Podcasts. Yaroslav Pedagogical Bulletin, $4(2), 165-167$.

Qaddour, K. (2017). The Use of Podcasts to Enhance Narrative Writing Skills. English Teaching Forum, 55(4), 28-31. Retrieved from

https://americanenglish.state.gov/files/ae/resource_files/etf_55_4_28-

31_title_the_use_of_podcasts_to_enhance_narrative_writing_skills_.pdf

Skalkin, V. (1983). Teaching English Monologue Production. Kiev: Radianska Shkola.

Skliarenko, N. (1995). Foreign Language Speaking Skills Assessment Criteria. In N. Skliarenko \& T. Oleinyk (Eds.), Integrated Book for Students and Lecturers of Pedagogical Universities (pp. 85-92). Horlovka, Ukraine: Horlovka State Pedagogical University of Foreign Languages.

Stanley, G. (2006). Podcasting: Audio on the Internet comes of age. TESL-EJ, 9(4), 1-7. Retrieved from: http://www.tesl-ej.org/pdf/ej36/int.pdf

Stepanova, S. (2011). Russian Speech Tempo (a Case Study of the "One Day of Speech" Corpus). Language and Speech, 11, 204-214.

Sysoiev, P. (2014). Podcasting in Language Teaching. Language and Culture, 2 (26), 189-201.

Travis, P., \& Joseph, F. (2009). Improving Learners' Speaking Skills with Podcasts. In M.

Thomas (Ed.), Handbook of Research on Web 2.0 and Second Language Learning (pp. 313330). Hershey, PA: Information Science Reference. https://doi.org/10.4018/978-1-60566-1902.ch017

Ustymenko, O. (2013). Teaching Monologue Production within the Competency-Based Approach. Foreign Languages, 2, 3-12.

Verkhovna Rada of Ukraine. (2014, July 1). The Law of Ukraine No. 1556-VII on "Higher Education." Official Bulletin of Ukraine, 63. Retrieved from https://zakon.rada.gov.ua/laws/show/1556-18\#Text

Waragai, I., Ohta, T., \& Raindl N. (2010). Podcasting Interaktiv - Lernende Produzieren Lernmaterialien. Gfl-journal, 1, 25-48. 